\title{
Compact UWB BPF with a Tunable Notched Band based on Triple- mode HMSIW Resonator
}

\author{
Chunxia Zhou ${ }^{*}$, Peipei Guo and Wen Wu
}

\begin{abstract}
Ministerial Key Laboratory of JGMT, Nanjing University of Science and Technology, Nanjing, 210094,China
\end{abstract}
\begin{abstract}
A novel triple-mode resonator based on the half-mode substrate integrated waveguide (HMSIW) structure is proposed to design the ultra-wideband (UWB) filters. The UWB filter topology is given by analyzing the resonant frequencies of the three modes and the signs of the coupling between the three modes and the input/output ports. With the filter synthesis method, a triple-mode UWB filter with passband from 3.1-10.6 $\mathrm{GHz}$ is effectively realized with two transmission zeros at the upper stopband. To block the existing undesired narrowband radio signals in FCC UWB range, a notched band can be easily generated and controlled by a loaded stub-capacitor. For demonstration, an UWB filter with a tunable notched band from 3.7 to $7.7 \mathrm{GHz}$ and compact size is designed and fabricated. Both simulated and measured results indicate that the proposed new filter has the properties of wide tuning range of the notched band and sharp roll off.
\end{abstract}

Index Terms: Filter; Half-mode substrate integrated waveguide (HMSIW); Tunable notch; Ultra-wideband (UWB).

(C) 2016 Published by MECS Publisher. Selection and/or peer review under responsibility of the Research Association of Modern Education and Computer Science

\section{Introduction}

Substrate integrated waveguide (SIW) techniques have been successfully applied to design various filters with low loss and high integration [1-3]. Wide bandwidth is one of the challenges in the design SIW filters as the week coupling between the SIW resonators. Electromagnetic bandgap (EBG) structure is used to design SIW filters with wide bandwith [4-6], which complicated the design and fabrication. Innovative SIW structures, such as the U-slotted SIW cavities [7] and the ridged half-mode substrate integrated waveguide (RHMSIW) [8] are recently reported to design wideband bandpass filters. However, the fractional bandwidth (FBW) is less than $50 \%$. Therefore, to design SIW filters with wide bandwidth is very meaningful.

Since the Federal Communication Commission (FCC) officially assigned an unlicensed use of ultrawideband (UWB) communication spectrum from 3.1 to $10.7 \mathrm{GHz}$ in 2002, various UWB filters have been

* Corresponding author: Chunxia Zhou

E-mail address: zhouchx1010@gmail.com 
reported [9-21]. Due to the existing undesired narrow band radio signals such as WLAN that may interfere with the FCC UWB range, UWB filters with a notched band are desired. The notched bands have been realized through various techniques, such as an embedded parasitic coupled line [12], an embedded $\lambda / 4$ slotline [13,14], a simplified composite right-/left-handed resonator [15], and asymmetric parallel-coupled lines [16,17]. As the existing undesired parasitic signals in the FCC UWB range change from place to place and from time to time, UWB filters with tunable notched band have been studied [18-21]. In [18,19], UWB filters with tunable notch have been developed with advanced technology such as silicon-based integrated passive device (IPD) and microelectromechanical system (MEMS), which require high cost and hybrid technology. Tunable notched UWB bandpass filters (BPFs) have been reported based on microstrip line in PCB technology in [20, 21]. However, they have suffered from narrow tuning rang of the notched band and poor attenuation of the passband edges.

In this letter, a novel triple-mode resonator based on half-mode substrate integrated waveguide (HMSIW) is proposed to design UWB filters. To our best knowledge, multiple-mode resonator (MMR) with HMSIW structure has not been studied in past literature thus far. By analyzing the resonant frequencies of the three modes and the signs of the coupling between the three modes and the input/output ports, the UWB filter topology is given. With the filter synthesis method, a triple-mode UWB filter with passband from 3.1-10.6 GHz is effectively realized with two transmission zeros at the upper stopband. To block the existing undesired narrowband radio signals in FCC UWB range, a notched band can be easily generated and controlled by a loaded stub-capacitor. For demonstration, an UWB filter with a tunable notched band from 3.7 to $7.7 \mathrm{GHz}$ and compact size is designed and fabricated. The UWB filter with high performance and wide tuning rang of the notched band are demonstrated in both simulated and measured results.

\section{Uwb Filter Design and Analysis}

\section{A. Triple-mode HMSIW resonator}

Fig. 1(a) shows the proposed triple-mode resonator, which consists of one section of HMSIW structure with length of $l_{1}$ and width of $w_{1}$, and two loaded stubs with length of $l_{2}$ and width of $w_{2}$. The electric field distributions of the first three excited modes are shown in Fig. 2. The field distributions of the first mode (Mode I) inside the resonator is similar to that of TE10 mode. The resonant frequency $f_{I}$ of Mode I can be expressed as

$$
f_{\mathrm{I}}=\frac{c}{4 l_{\mathrm{I} e q} \sqrt{\varepsilon_{r}}}
$$

where $c$ is the speed of light in free space, $\varepsilon_{r}$ is the effective dielectric constant of the substrate, and $l_{\text {leq }}$ denotes the effective length of the triple-mode resonator for Mode I, which is a little less than $l_{1}+l_{2}$.

While for the second mode (Mode II), the electric field distributes mainly on the loaded stubs. Thus, Mode II is excited by the quarter wavelength of the loaded stubs. The resonant frequency $f_{\text {II }}$ of Mode II can be expressed as

$$
f_{\mathrm{II}}=\frac{c}{4 l_{2} \sqrt{\varepsilon_{r}}}
$$

While the third mode (Mode III) is the third harmonic of Mode I. The resonant frequency $f_{\text {III }}$ of Mode III can be expressed as 


$$
\mathrm{f}_{\mathrm{III}}=\frac{3 c}{4 l_{\mathrm{IIIeq}} \sqrt{\varepsilon_{r}}}
$$

where $l_{\text {IIIeq }}$ denotes the effective length for Mode III, which is approximate to $l_{1}+l_{2}$.

As an example, Roger 5880 substrate with $0.787 \mathrm{~mm}$ thickness is adopted with $w_{1}=6.5 \mathrm{~mm}, l_{1}=10.5 \mathrm{~mm}$, $w_{2}=0.8 \mathrm{~mm}$. The resonant frequencies of the first three excited modes versus $l_{2}$ are shown in Fig. 3 using Eigenmode simulator in HFSS software (keeping $l_{1}+l_{2}$ unchanged). The resonant frequency of the first mode increases slightly, and the third mode decreases slightly, while the second mode decreases greatly with the increase of $l_{2}$.

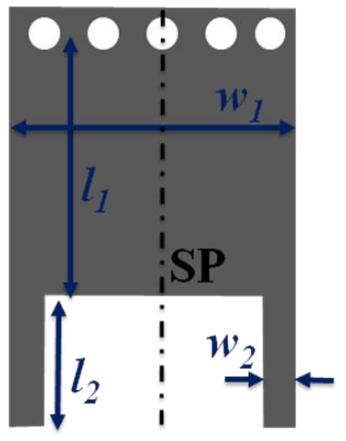

(a)

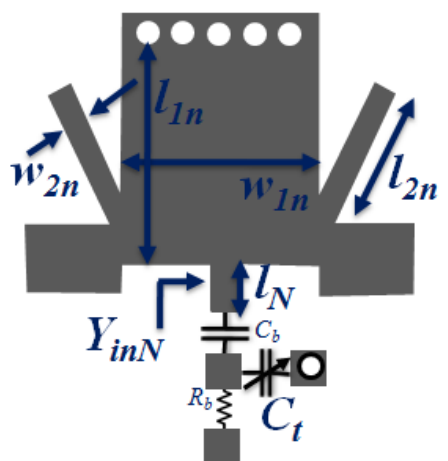

(b)

Fig.1. Geometry of the proposed (a) Triple-mode resonator and; (b) UWB filter with a tunable notched band.

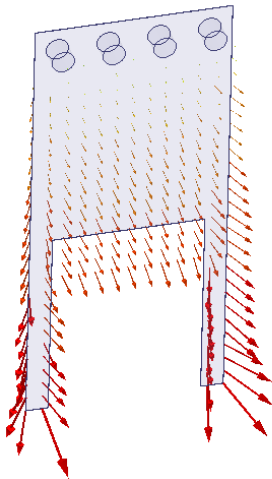

(a)

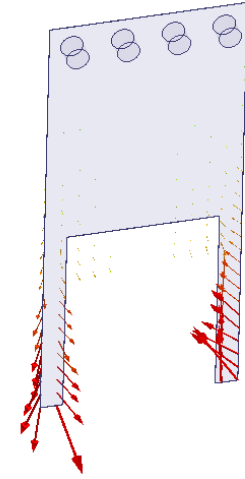

(b)

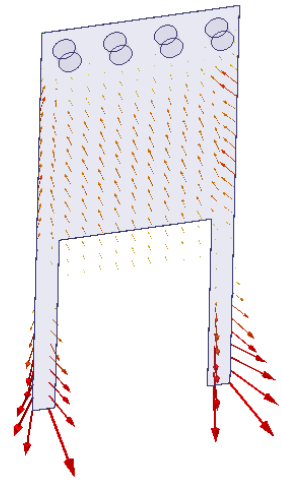

(c)

Fig.2. Distributions of electric field magnitude inside the triple-mode resonator. (a) Mode I ;(b) Mode II; (c) Mode III.

\section{B. UWB filter design}

As can be observed from Fig. 2, the electric field distribution of Mode I and Mode III is even-symmetric, while Mode II is odd-symmetric with respect to the symmetrical plane [SP in Fig. 1(a)]. Therefore, the signs of coupling coefficients between Mode I or Mode III and input/output are the same, while the signs of coupling coefficients between Mode II and input/output are opposite. Based on the phenomenon described, coupling 
scheme of the UWB filter based on triple-mode HMSIW resonator can be defined as illustrated in Fig. 4(a). Corresponding coupling matrix M can be synthesized with one transmission zero at the upper stopband by [22] and the synthesized S-parameters are shown in Fig. 4(b).

$$
M=\left[\begin{array}{ccccc}
0 & 0.2774 & 0.7719 & 0.7204 & 0 \\
0.2774 & -1.2204 & 0 & 0 & 0.2774 \\
0.7719 & 0 & -0.7819 & 0 & -0.7719 \\
0.7204 & 0 & 0 & 1.5330 & 0.7204 \\
0 & 0.2774 & -0.7719 & 0.7204 & 0
\end{array}\right]
$$

Depending on the above analyses, a UWB filter is design, simulated, and fabricated. Fig. 5 shows the simulated and measured frequency responses of the filter with passband from 3.1-10.7 GHz. As can be seen from the figure, there is a good agreement between the predicted and measured results. Two transmission zeros at 11.2 and $13.4 \mathrm{GHz}$ are observed in the upper stopband. The transmission zero at $11.2 \mathrm{GHz}$ is inherent in the filter topology and the transmission zero at $13.4 \mathrm{GHz}$ is generated by the loaded stubs at half wavelength.

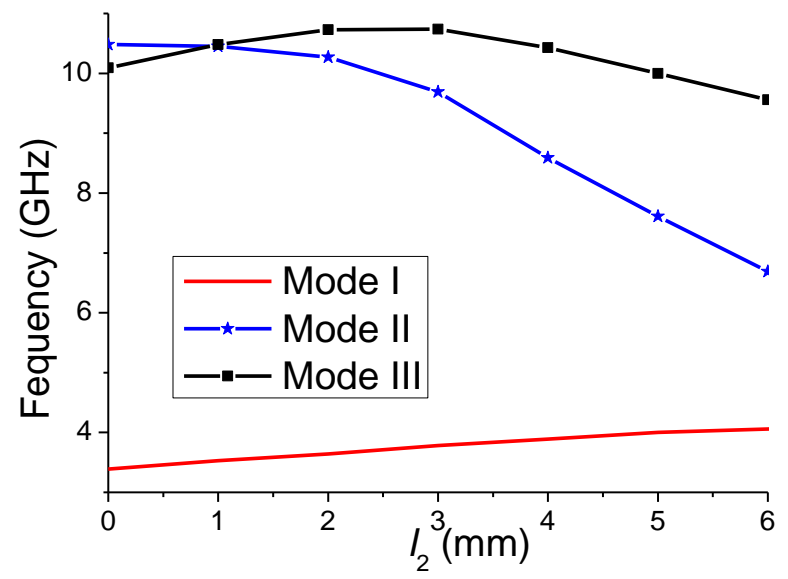

Fig.3. The relationship between the resonant frequencies of the first three excited modes and the stub length $l_{2}$.

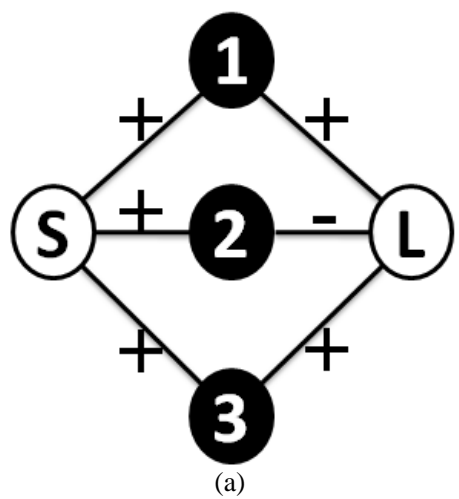




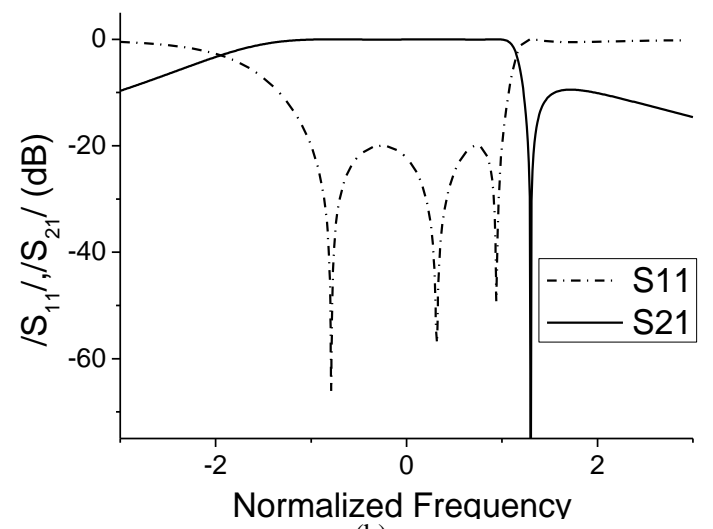

(b)

Fig.4. (a) Topology and (b) Synthesized S-parameters of the proposed triple-mode filter.

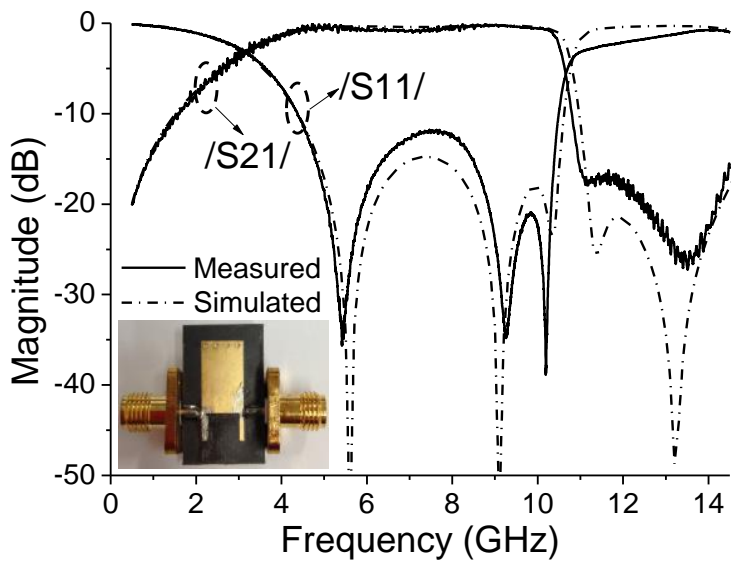

Fig.5. Measured and simulated responses of the UWB filter.

\section{Uwb Filter with a Tunable Notched Band}

As shown in Fig.1 (b), the proposed UWB BPF with a tunable notched band can be realized by connecting a loaded stub-capacitor to the triple-mode HMSIW resonator. The notched frequency $f_{N}$ can be obtained by

$$
Y_{i n N}=Y_{N} \frac{j 2 \pi f_{N} C_{t}+j Y_{N} \tan \theta_{N}}{Y_{N}-2 \pi f_{N} C_{t} \tan \theta_{N}}=\infty
$$

That is

$$
f_{N}=\frac{Y_{N}}{2 \pi C_{t} \tan \theta_{N}}
$$


where $Y_{\text {inN }}$ is input impedance of the loaded stub-capacitor, $C_{t}$ is the capacitance of the loaded varactor, and $Y_{N}$ and $\theta_{N}$ is the impedance and electric length of the loaded stub, respectively.

For facilitating the DC bias circuit, the two loaded stubs are turned to the upper side of the HMSIW resonator. The dimensions for the proposed UWB filter in Fig. 1(b) are designed as follows: $w_{1 \mathrm{n}}=6.1 \mathrm{~mm}$, $l_{1 \mathrm{n}}=10 \mathrm{~mm}, w_{2 \mathrm{n}}=0.8 \mathrm{~mm}, l_{2 \mathrm{n}}=4.5 \mathrm{~mm}$, and $l_{\mathrm{n}}=0.9 \mathrm{~mm}$. A MA46H120 varactor is used in the prototype circuit. The varactor capacitance is 200 and $1200 \mathrm{fF}$ at 10 and $0 \mathrm{~V}$ reverse bias, respectively. The DC bias is fed to the varactor through the DC block capacitors $C_{\mathrm{b}}$ and the resistors $R_{\mathrm{b}}$ are utilized as RF blockage elements. Fig. 6 shows the simulated and measured $S_{21}$ of the tunable filter. When the bias voltage $V_{c}$ varies from 0 to $10.0 \mathrm{~V}$, the notched frequency is tuned from 3.7 to $7.7 \mathrm{GHz}$. The return loss is better than $13 \mathrm{~dB}$ within the tuning range. Photograph of the fabricated BPF is presented in Fig. 7 with a circuit size (including the bias circuit and input/out output ports) of $12.1 \mathrm{~mm} * 14.7 \mathrm{~mm}$, i.e., $0.46 \lambda_{\mathrm{g}} * 0.38 \lambda_{\mathrm{g}}$, where $\lambda_{\mathrm{g}}$ is the guided wavelength of $50-\Omega$ microstrip line at the central frequency of $6.85 \mathrm{GHz}$. Comparisons with other reported UWB BPFs with notched band are listed in Table1, which shows that the proposed UWB filter has a notched band with wide tuning range, easy fabrication and a compact size.

Table 1. Comparison with the reported UWB BPFs with notched band

\begin{tabular}{c|c|c|c|c} 
Ref. & Size & Notch frequency $(\mathrm{GHz})$ & Technology & Tunablity \\
\hline$[12]$ & $0.66 \lambda_{\mathrm{g}} * 0.36 \lambda_{\mathrm{g}}$ & 7 & PCB & No \\
\hline$[13]$ & $0.30 \lambda_{\mathrm{g}} * 0.17 \lambda_{\mathrm{g}}$ & 5.8 & PCB & No \\
\hline$[14]$ & $1.68 \lambda_{\mathrm{g}} * 0.5 \lambda_{\mathrm{g}}$ & 8.07 & PCB & No \\
\hline$[15]$ & $1.10 \lambda_{\mathrm{g}} * 0.63 \lambda_{\mathrm{g}}$ & $5.85 / 8.05$ & PCB & No \\
\hline$[16]$ & $0.63 \lambda_{\mathrm{g}} * 0.13 \lambda_{\mathrm{g}}$ & 5.59 & PCB & No \\
\hline$[17]$ & $1.03 \lambda_{\mathrm{g}} * 0.57 \lambda_{\mathrm{g}}$ & 5.41 & PCB & No \\
\hline$[18]$ & $4.8 \mathrm{~mm} * 2.9 \mathrm{~mm}$ & $3.5-6.5$ & IPD & Yes \\
\hline$[19]$ & $10 \mathrm{~mm} * 2.5 \mathrm{~mm}$ & $6.3-7.7$ & MEMS & Yes \\
\hline$[19]$ & $10 \mathrm{~mm} * 2.5 \mathrm{~mm}$ & $5.5-6.45 / 7.8-8.8$ & Yes \\
\hline$[20]$ & $20 \mathrm{~mm} * 40 \mathrm{~mm}$ & $3.65-4.35$ & PCB & Yes \\
\hline$[21]$ & $1.1 \lambda_{\mathrm{g}} * 0.63 \lambda_{\mathrm{g}}$ & $5.45-6.07$ & PCB & Yes \\
\hline This work & $\mathbf{0 . 4 6} \lambda_{\mathrm{g}} * \mathbf{0 . 3 8} \lambda_{\mathrm{g}}$ & $\mathbf{3 . 7 - 7 . 7}$ & PCB & Yes
\end{tabular}

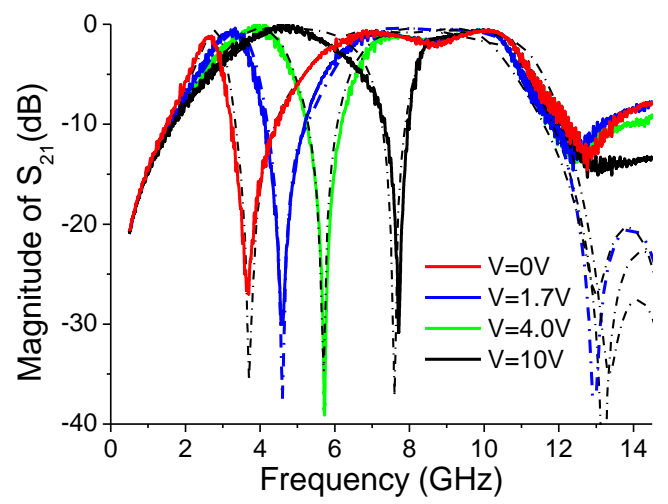

(a) 


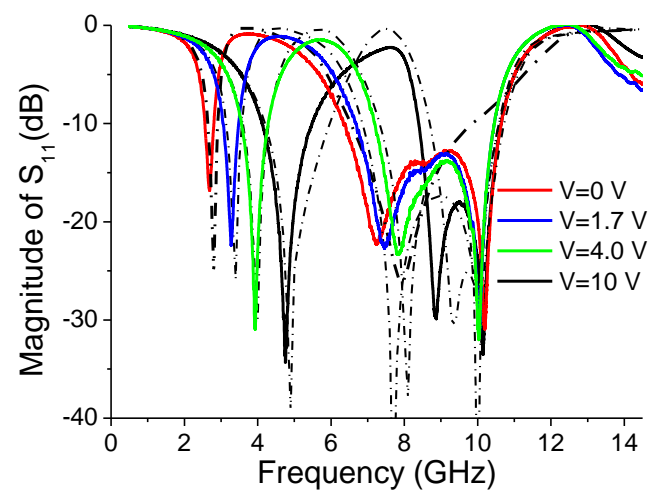

(b)

Fig.6. Measured and simulated responses of the UWB filter with a tunable notched band .(a) S21; (b) S11.

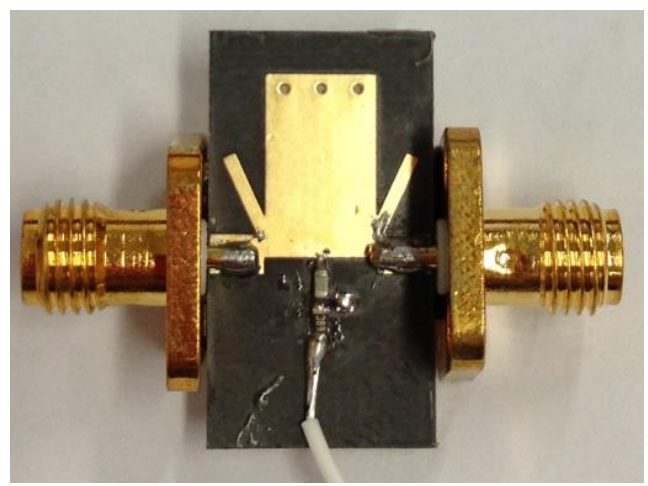

Fig.7. Photograph of fabricated UWB filter with tunable notch.

\section{Conclusions}

A novel UWB filter with a tunable notched band is presented in this letter based on triple-mode HMSIW resonator. The triple-mode characteristic of the proposed resonator is analyzed. By altering the lengths of the loaded-stubs, the frequencies of the three modes can be allocated evenly in the UWB band. Also, two transmission zeros are produced at the upper stopband to improve attenuation of the passband edges. Simultaneously, a notched band with wide tuning range $(3.7 \mathrm{GHz}-7.7 \mathrm{GHz})$ can be realized by employing a varactor diode. Good agreement between the simulation and the measurement results demonstrates the validity of the design.

\section{Acknowledgements}

This work was supported by the National Natural Science Foundation Committee of China (61401202). 


\section{References}

[1] Chen, X.; Hong, W.; Cui, T.; Chen, J.; Wu, K.: Substrate integrated waveguide linear phase filter, IEEE Microwave Wireless Compon. Lett., 15 (2005), 787-789.

[2] Wu, L.; Zhou, X.; Zhou, L.; Yin, W.; Mao, J.: A substrate integrated evanescent-mode waveguide filter with nonresonating node in low temperature co-fired ceramic, IEEE Trans. Microw. Theory Tech., 58 (2010), 2654-2662.

[3] Hu, G.; Liu, C.; Yan, L.; Huang, K; Menzel, W: Novel dual mode substrate integrated waveguide bandpass filters. J. Electromagn. Waves Appl. 24 (2010), 1661-1672.

[4] Hao, Z.; Hong, W; Chen, J; Chen, X; Wu, K: Compact super-wide bandpass substrate integrated waveguide filters, IEEE Trans. Microwave Theory Tech., 53 (2005), 2968-2977.

[5] Wu, L.; Zhou, X; Yin, W.: Ultra-wideband bandpass filter using half-mode T-septum substrate integrated waveguide with electromagnetic bandgap structures, Microw. Opt. Technol. Lett., 51 (2009), 1751-1755.

[6] Chu, H; Shi, X.: Compact Ultra-Wideband Bandpass Filter Based on SIW and DGS Technology with a Notch Band. J. Electromagn. Waves Appl. 25 (2012), 589-596.

[7] Chen, R.; Wong, S.; Zhu, L.; Chu, Q.: Wideband Bandpass Filter Using U-Slotted Substrate Integrated Waveguide (SIW) Cavities, IEEE Microw. Wirel. Compon. Lett., 25 (2015), 1- 3.

[8] Huang, L.; Cha, H.: Compact Ridged Half-Mode Substrate Integrated Waveguide Bandpass Filter, IEEE Microw. Wirel. Compon. Lett., 25 (2015), 223- 225.

[9] Zhu, L.; Sun, S.: Ultra-wideband (UWB) bandpass filters using multiple-mode resonator, IEEE Microw. Wirel. Compon. Lett., 15 (2005), 796- 798.

[10] Chun, Y.; Shaman, H.; Hong, J.: Switchable embedded notch structure for UWB bandpass filters, IEEE Microw. Wirel. Compon. Lett., 18 (2008), 590-592.

[11] Pankaj, S.; Ishita, R.; Sharmili, A.: A band notch UWB bandpass filter using dual-stub-loaded multimode resonator with embedded spiral resonator. Int. J. Microw. Wirel. Technol., 6 (2014), 161-166.

[12] Pirani, S.; Nourinia, J.; Ghobadi, C.: Band-notched UWB BPF design using parasitic coupled line, IEEE Microw. Wirel. Compon. Lett., 20 (2010), 444-446.

[13] Luo, X.; Ma, J.; Ma, K.; Yeo, K.: Compact UWB bandpass filter with ultra narrow notched band, IEEE Microw. Wirel. Compon. Lett., 20 (2010), 145-147.

[14] Gholamreza, K.; Farnaz, K.; Hesam, S.: Compact UWB BPF using slotted resonator with an independently controllable notched band. Int. J. Microw. Wirel. Technol., 8 (2016), 25-31.

[15] Wei, F.; Wu, Q.; Shi, X.; Chen, L.: Compact UWB bandpass filter with dual notched bands based on SCRLH resonator, IEEE Microw. Wireless Compon. Lett., 21 (2011), 28-30.

[16] Wong, S.; Zhu, L.: Implementation of compact UWB bandpass filter with a notch-band, IEEE Microw. Wireless Compon. Lett., 18 (2008), 10-12.

[17] Kim, C.; Chang, K.: Ultra-wideband (UWB) ring resonator bandpass filter with a notched band, IEEE Microw. Wirel. Compon. Lett., 21 (2011), 206-208.

[18] Wu, Z.; Shim, Y.; Pistono, E.; Mina, R.: Miniaturized UWB Filters Integrated With Tunable Notch Filters Using a Silicon-Based Integrated Passive Device Technology, IEEE Trans. Microw. Theory Tech., 60 (2012), 518-527.

[19] Nosrati, M.; Vahabisani, N.; Daneshmand, M.: Compact MEMS-Based Ultrawide-Band CPW Band-Pass Filters With Single/Double Tunable Notch-Bands, IEEE Trans. Compon. Packag. Manuf. Tech., 4 (2014), 1451-1460.

[20] Yamamoto, Y.; Li, K.; Hashimoto, O.: Tunable sharp notch filter for UWB application, Microw. Opt. Technol. Lett., 50 (2008), 2712-2715.

[21] Wei, F.; Chen, L.; Shi, X.; Liu, B.: Compact UWB bandpass filter with tunable notch band based on folded SIR, Electron. Lett., 47 (2011), 1229-1230. 
[22] Cameron, R.: Advanced coupling matrix synthesis techniques for microwave filters, IEEE Trans. Microw. Theory Tech., 51 (2003), 1-10.

\section{Authors' Profiles}

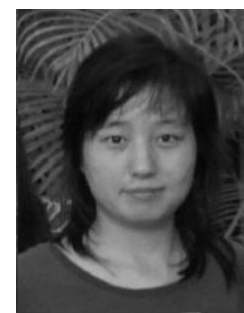

Chunxia Zhou (M'14) was born in Jiangsu Province, China, in 1985. She received the B.S. and $\mathrm{Ph} . \mathrm{D}$ degree in electronic engineering from Nankai University, Tianjin, China, in 2007 and 2012, respectively.

From September 2010 to February 2012, she was a joint Ph.D. student with the Department of Electrical and Computer Engineering, National University of Singapore (NUS), Singapore. From December 2012 to July 2012, she was a Research Fellow with Terahertz Science and Technology Research Center of China Academy of Engineering Physics, Chengdu, China. She is currently a lecture with the School of Electronic Engineering and Optoelectronic Technology, Nanjing University of Science and Technology, Nanjing, China. Her research interests include the design and optimization of microwave and millimeter-wave circuits, and microwave and millimeter-wave integrated circuits in CMOS technology.

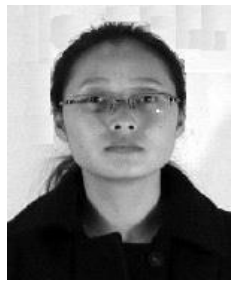

Peipei Guo was born in Jiangsu Province, China, in 1990. She is currently working toward the Ph.D. degree in electronic engineering, Nanjing University of Science and Technology (NUST), Nanjing, China.

Her current research interests include microwave passive components.

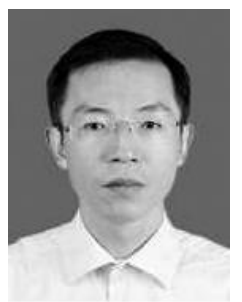

Wen $\mathbf{W u}\left(\mathrm{SM}^{\prime} 10\right)$ received the Ph.D. degree in electromagnetic field and microwave technology from Southeast University, Nanjing, China, in 1997.

He is currently a Professor with the School of Electronic Engineering and Optoelectronic Technology and an Associate Director with the Ministerial Key Laboratory of JGMT, Nanjing University of Science and Technology, Nanjing,

China. He has authored and coauthored over 120 journal and conference papers. He has submitted five patent applications. His current research interests include microwave and millimeter-wave (mm-wave) theories and technologies, microwave and mm-wave detection, and multimode compound detection.

Dr. Wu was a six-time recipient of the Ministerial and Provincial-Level Science and Technology Award.

How to cite this paper: Chunxia Zhou, Peipei Guo, Wen Wu,"Compact UWB BPF with a Tunable Notched Band based on Triple-mode HMSIW Resonator", International Journal of Wireless and Microwave Technologies(IJWMT), Vol.6, No.5, pp.1-9, 2016.DOI: 10.5815/ijwmt.2016.05.01 